\title{
Identity Negotiation: Where Two Roads Meet
}

\author{
William B. Swann, Jr. \\ University of Texas at Austin
}

\begin{abstract}
This article traces a program of research on the interplay between social thought and social interaction. Early investigations of the impact of perceivers' expectancies on the actions of target individuals illuminated the contribution of perceivers to the identity negotiation process but overlooked the role of targets. The research discussed here is based on the assumption that targets play an active role in the identity negotiation process. Specifically, just as perceivers strive to validate their expectancies, targets seek to verify their self-views. The nature and antecedents of the processes through which people verify their self-conceptions as well as the relationship of these activities to self-concept change and self-enhancement processes are discussed. This research suggests that perceivers and targets enter their interactions with independent and sometimes conflicting agendas that are resolved through a process of identity negotiation. The identity negotiation process therefore provides a theoretical context in which the interplay between other-perception and self-perception can be understood.
\end{abstract}

A little over a decade ago, Mark Snyder and I became interested in the self-fulfilling nature of social beliefs. We were particularly interested in behavioral confirmation, a process whereby the expectancies of some individuals (perceivers) channel social interaction so as to cause the behavior of other individuals (targets) to confirm perceivers' expectancies. In our research, for example, targets labeled as hostile grew aggressive, those believed to be extraverted became sociable, and those thought to be bright blossomed into star performers (e.g., Snyder \& Swann, 1978a, 1978b; Swann \& Snyder, 1980; for a review, see Snyder, 1984). On the basis of these and earlier findings (e.g., S. C. Jones \& Panitch, 1971; Kelley \& Stahelski, 1970; Rosenthal \& Jacobson, 1968; Word, Zanna, \& Cooper, 1974; Zanna \& Pack, 1975), we concluded that there might exist a pervasive tendency for the beliefs of perceivers to shape the nature of social reality.

Yet the behavioral confirmation formulation seemed to illuminate only a portion of what was happening in our studies. True, most target individuals in our research did behaviorally confirm the expectancies of perceivers (see also Darley \& Fazio, 1980; E. E. Jones, 1986; Miller \& Turnbull, 1986). It was also true, however, that some targets vehemently resisted the labels with which they were tagged. Apparently, targets had their own

The research and the preparation of this article were supported by Grant MH 37598 and Research Scientist Development Award MH 00498 to me from the National Institute of Mental Health. I am grateful to Jonathon Brown, Bella DePaulo, Daniel Gilbert, Nancy Hazen, Ned Jones, and Brett Pelham for helpful comments on an earlier version of this article.

Correspondence concerning this article should be addressed to William B. Swann, Jr., Department of Psychology, University of Texas, Austin, Texas 78712 . ideas about themselves and social reality, and at least on occasion, they took active steps to ensure that perceivers shared those ideas. Social reality was not simply constructed by perceivers acting alone; it was negotiated by perceivers and targets acting together. It seemed crucial to learn more about the contribution of targets to the negotiation process.

This article offers one perspective on the role of targets in the identity negotiation process. The central notion is that targets want perceivers to see them as they see themselves, an idea that was advanced by Lecky (1945) and has since been elaborated by several others, most notably Carson (1969), Harvey, Hunt, and Schroder (1961), and especially Secord and Backman (1965). The self-verification formulation (Swann, 1983, 1985) represents a synthesis and extension of these earlier works.

One of my major objectives will be to identify various strategies of self-verification and the personal and situational factors that set them in motion. A second goal will be to consider two propositions that compete with various aspects of the self-verification formulation: the notion that self-concepts are highly malleable and the contention that people strive to enhance rather than maintain their self-views. A final goal will be to argue that the relative expansiveness of an identity negotiation framework makes it capable of offering insights into questions that cannot be understood from narrower perspectives. For this reason, I urge future researchers to adopt an identity negotiation framework. I begin with a discussion of the antecedents of the self and self-verification processes.

\section{Self-Verification Processes}

In the tradition of the symbolic interactionists (e.g., Cooley, 1902; Mead, 1934), I assume that people have a fundamental desire to know what to expect from their worlds. Toward this 
end, they observe their own behavior, the reactions of others to them, and the relation of their own performances to those of others; gradually, they translate these observations into selfconceptions.

As children gather more and more evidence on which to base their self-conceptions, they begin to work to confirm these conceptions. In part, such activity grows out of purely epistemic considerations. Studies of judgmental processes, for example, have indicated that people are more likely to seek and rely on evidence that confirms rather then disconfirms their hypotheses and beliefs, presumably because they find such confirmatory evidence to be particularly trustworthy, diagnostic, and easy to process (e.g., Bruner, Goodnow, \& Austin, 1956; Klayman \& Ha, 1987; Snyder \& Swann, 1978b; Wason \& Johnson-Laird, 1972). This suggests that there may be a fundamental, cognitively based tendency for people to regard information that confirms their self-conceptions as more diagnostic than information that disconfirms their self-conceptions. In support of this hypothesis, participants in a study by Swann and Read (1981a, Study 3 ) indicated that they could learn more about themselves by examining self-confirmatory information as compared with self-disconfirmatory information.

Even if people did not believe that self-confirmatory evidence was especially informative, they might still seek such evidence because it fosters a sense of existential security. That is, in a world in which one's surroundings, interaction partners, and rules governing survival may change rapidly, stable self-conceptions may play an important role in organizing experience, predicting future events, and guiding behavior (cf. Epstein, 1973; Lecky, 1945; Mead, 1934; Secord \& Backman, 1965). Self-conceptions may therefore be construed as the lenses through which people view the world, the means whereby they define their existence and understand the world around them. Thus, substantial changes in self-conceptions may necessitate massive reorganization of the conceptual systems through which they make sense of their world.

People may also resist changes in their self-conceptions for pragmatic reasons. People who know that they lack particular abilities, for example, may resist changes in the associated selfconceptions lest they venture into situations in which they will fail miserably (e.g., Baumgardner \& Brownlee, 1987). In addition, people may fear that marked changes in their self-views will sour their relationships, as their interaction partners typically expect them to honor the identities that they have negotiated with them earlier (Athay \& Darley, 1981; Swann, 1984).

For these and other reasons, people are likely to think and behave in ways that promote the survival of their self-conceptions, regardless of whether the self-conception happens to be positive or negative. Although there are surely painful consequences associated with verifying negative self-conceptions, the foregoing analysis suggests that failing to verify them may have even more painful consequences both epistemically and pragmatically.

Recent research has supported the notion that people work to verify their self-conceptions by striving to acquire self-confirmatory feedback. For example, in a series of three studies, Swann and Read (1981b) found clear evidence of a preference for self-confirmatory feedback whether they examined the extent to which participants paid attention to such feedback, re- membered it, or actively sought it. Three additional investigations by Swann and Read (1981a) showed that both men and women preferentially solicited self-confirmatory feedback pertaining to valenced as well as unvalenced self-concepts. Furthermore, people were undaunted in their quest for self-confirmatory feedback even when they had reason to believe that it would make them depressed (Swann, Krull, \& Predmore, 1987) and even when they had to spend their personal funds to get it (Swann \& Read, 1981a).

The specific strategies through which people verify their selfconceptions fall into two distinct classes. Within the first class are behavioral activities through which targets strive to control the reactions of perceivers. Specifically, targets work to create around themselves self-confirmatory opportunity structures (McCall \& Simmons, 1966), that is, social environments that foster the survival of their self-views.

Within the second class of self-verification strategies are cognitive processes through which targets systematically distort their perceptions of social reality. In particular, targets process feedback from perceivers in ways that make perceivers' responses seem more supportive of their self-views than they actually are. I will now take a closer look at these strategies of selfverification.

\section{Developing a Self-Confirmatory Opportunity Structure}

For some years, biologists and ecologists have noticed that every living organism inhabits a niche or opportunity structure that routinely satisfies its needs and desires (cf. Clarke, 1954; Odum, 1963; E. O. Wilson, 1974). People are no exception to this rule. In fact, people seem to be particularly active in striving to ensure that their opportunity structures satisfy their desire for self-confirmatory feedback (e.g., McCall \& Simmons, 1966).

In their quest for a self-confirmatory opportunity structure, people may use at least three strategies: They may strategically choose interaction partners and social settings, they may display identity cues, and they may adopt interaction strategies that evoke self-confirmatory responses.

\section{Selective Interaction}

For years, researchers have been intrigued with the notion that people seek out social contexts that will provide them with self-confirmatory feedback. Although it is very difficult to obtain definitive support for this hypothesis, several researchers have collected correlational evidence that is consistent with it. Pervin and Rubin (1967), for example, have found that students are less likely to drop out and are happier in college if it has qualities that are compatible with their self-views (see also Backman \& Secord, 1962; Broxton, 1963; Newcomb, 1956).

My students and I have collected somewhat more direct evidence for the selective interaction hypothesis. For example, Swann and Pelham (1987, Study 1) found a highly reliable tendency for people to prefer their ideal friends and intimates to see them as they saw themselves $(F s>100)$. Thus, just as people who had positive self-conceptions preferred others to view them favorably, people who had negative conceptions of themselves preferred others to view them relatively unfavorably. A second 
series of investigations by Pelham and Swann (1987a) indicated that people's preferences for friends with either favorable or unfavorable appraisals were associated with the actual appraisals of their friends $(r=.65)$, thus suggesting that people translate their desire for congruent relationship partners into actual selection of partners.

Further support for the selective interaction hypothesis comes from a field investigation of college roommates by Swann and Pelham (1987, Study 2). They discovered that individuals who found themselves in relationships in which their roommate's appraisal was incongruent with their self-conceptions were more likely to plan to change roommates than were those in congruent relationships. Moreover, this tendency was symmetrical with respect to self-esteem; people with negative self-conceptions were just as eager to flee from overly favorable roommates as people with positive self-conceptions were inclined to flee from overly unfavorable roommates.

These data therefore offer fairly clear evidence that people gravitate toward social relationships in which they are apt to receive self-confirmatory feedback. An important characteristic of this selective interaction strategy is that once people enter a particular social relationship or institution, forces such as legal contracts and inertia will tend to keep them there. Hence, the selective interaction strategy of self-verification tends to lock people into an interpersonal feedback system that will often be self-sustaining as well as self-verifying.

\section{Displaying Identity Cues}

Another way that people can succeed in laying claim to a particular identity is by looking the part. To be effective, identity cues must meet two criteria: They must be under the individual's control, and they must characteristically evoke desired responses from others.

People's physical appearance represents one class of identity cues. The clothes one wears, for example, can be used to tell others whether one is liberal or conservative, wealthy or destitute, easygoing or meticulous, prudish or promiscuous. Similarly, through the skillful use of cosmetics and wigs, people can project dramatically different identities to onlookers. Even body posture may be used to communicate various identities to others. Take, for example, the sex symbol who is forever striking a seductive pose or the aristocrat who never lets bearing belie his or her sense of dignity.

Given sufficient motivation, people may actually modify their body structure to convey particular identities to others. Selfperceived athletes, for example, may diet and lift weights to ensure that their physiques elicit the reactions they crave. Aging individuals who wish to retain their youthful appearance may take more drastic steps. With a little surgery, sagging breasts can regain their former stature, tummies can be tucked, and balding pates can go under cover again. And there is hope even for those who are wimpy about weights and squeamish about surgery, for they may accumulate and display various material possessions. The cars people drive, the homes they live in, the trophies they display in their den may all be used to tell others who they are and how they expect to be treated (cf. Goffman, 1959; Schlenker, 1980).

If physical appearances do not suffice, people may ensure that they are understood by relying on social conventions such as titles and occupational labels. In this way, people may ensure that before they even open their mouths, others know a great deal about the identities that they wish to assume.

\section{Interaction Strategies}

Even if people fail to acquire self-confirmatory feedback through selective interaction by displaying identity cues, they may still acquire such feedback by adopting appropriate interaction strategies. Swann and Read (1981b, Study 2), for example, had targets who perceived themselves as either likable or dislikable interact with perceivers. Some targets were led to suspect that the perceiver might like them; others learned that the perceiver might dislike them; still others learned nothing of the perceiver's evaluation of them.

There was an overall tendency for targets who perceived themselves as likable to elicit more favorable reactions than did targets who perceived themselves as dislikable. Moreover, this tendency was especially pronounced when targets suspected that perceivers' appraisals might disconfirm their self-conceptions. Just as targets who thought of themselves as likable and suspected that perceivers disliked them elicited the most favorable reactions, those who saw themselves as dislikable and suspected that perceivers liked them elicited the least favorable reactions. Therefore, targets were particularly inclined to elicit self-confirmatory feedback from perceivers when they suspected that perceivers' appraisals were incompatible with their self-views (cf. Hilton \& Darley, 1985).

Swann and Hill (1982) obtained a similar pattern of results using another dimension of the self-concept (dominance) and a different procedural paradigm. Targets began by playing a game with a confederate in which each player alternately assumed the dominant "leader" role or the submissive "assistant" role. There was a break in the game, and the experimenter asked the players to decide who would like to be the leader for the next set of games. This signaled the confederate to deliver feedback to the target. In some conditions, the confederate indicated that the target seemed dominant and in other conditions asserted that the target seemed submissive.

If the feedback confirmed targets' self-conceptions, they more or less passively accepted the confederate's appraisal. If the feedback disconfirmed their self-conceptions, however, targets reacted quite vehemently, resisting the feedback and bending over backwards to demonstrate that they were not the persons the confederate made them out to be. Thus, self-conceived dominants who were labeled submissive became particularly dominant, and self-conceived submissives who were labeled dominant became especially submissive.

An interesting feature of the Swann and Hill study was that some people resisted the discrepant feedback more than others did. Swann and Ely (1984) speculated that such differences in resistance might reflect variability in the extent to which people were certain of their self-conceptions. They reasoned that as people become more certain of their self-conceptions, they will be more inclined to rely on these conceptions to organize their experiences, predict future events, and guide behavior. For this reason, the more certain people are of their self-conceptions, the more motivated they should be to defend them against threats. 
To test this hypothesis, Swann and Ely (1984) had perceivers interview targets who were either certain or uncertain of their self-conceived extraversion. Perceivers were always provided with an expectancy about targets that was discrepant with the self-conceptions of targets. This created the potential for a battle of wills, with perceivers' experimentally manipulated beliefs vying against targets' chronic self-views. Consistent with earlier research by Snyder and Swann (1978b; see also Swann \& Giuliano, in press), perceivers acted on their expectancies by encouraging targets to make self-discrepant statements. Targets who were low in self-certainty tended to answer in ways that confirmed perceivers' expectancies (but disconfirmed their own self-conceptions) when perceivers were highly certain of their expectancies. In contrast, targets who were high in self-certainty actively resisted perceivers' questions, eventually bringing perceivers to revise their expectancies in favor of targets' chronic self-views. Thus, when targets were high in self-certainty, selfverification "won" over behavioral confirmation in the battle of wills (for a discussion of other factors that influence the outcome of such battles, see Swann, 1984).

Together, our findings suggest that an important determinant of the outcome of the identity negotiation process is the efforts of targets to bring perceivers to see them as they see themselves. Nevertheless, as effective as such efforts may often be, people may sometimes fail to create a self-confirmatory opportunity structure through their behavioral self-verification strategies. When these self-verification strategies fail, the survival of people's self-views may hinge on the effectiveness of the three cognitive self-verification strategies described in the next section.

\section{Seeing More Self-Confirmatory Evidence Than Actually Exists}

When people encounter self-disconfirmatory feedback, it is not necessarily the end of the line for the self-conception in question. Researchers have shown that expectancies in general and self-conceptions in particular exert a powerful channeling influence on information processing (for reviews, see Higgins \& Bargh, 1987; Kihlstrom \& Cantor, 1984). This introduces the possibility that self-conceptions guide the processing of social feedback so as to promote their own survival.

\section{Preferential Attention}

To the extent that people are motivated to acquire self-confirmatory feedback, they should be especially attentive to it. A study by Swann and Read (1981b, Study 1) supported this hypothesis. Target individuals who perceived themselves as likable or dislikable learned that another person had evaluated them. Some targets were led to suspect that the other person had formed a favorable impression of them; others were led to suspect that the other person had formed an unfavorable impression of them. All were then given an opportunity to examine a series of statements that the other person had ostensibly made about them. These statements were sufficiently vague and general so as to apply to anyone.

The results showed that targets spent more time scrutinizing the evaluative statements when they anticipated that the statements would confirm their self-conceptions. That is, just as peo- ple who saw themselves as likable spent more time scrutinizing the statements when they expected them to be favorable, those who saw themselves as dislikable spent more time scrutinizing the statements when they expected them to be unfavorable. Hence, it appears that people will be more attentive to social feedback if they suspect that it will confirm their chronic selfviews.

\section{Selective Encoding and Retrieval}

Just as people may preferentially attend to self-confirmatory feedback, they may also encode and recall it preferentially. Crary (1966) and Silverman (1964), for example, reported that people recalled more incidental information about experimental tasks in which they received self-confirmatory rather than self-discrepant feedback.

Self-conceptions seem to channel the type as well as the amount of feedback that people recall. Swann and Read (1981b, Study 3) had participants who perceived themselves as likable or dislikable listen to another individual make a series of positive and negative statements about them. Some participants expected that the statements would be generally positive; others expected that the statements would be generally negative. After a brief delay, participants recalled as many of the statements as possible. Overall, those who saw themselves as likable remembered more positive statements and those who saw themselves as dislikable remembered more negative statements. In addition, this tendency to recall more self-confirmatory statements than self-disconfirmatory statements was greatest when individuals anticipated that their interaction partner's statements would confirm their self-conceptions.'

\section{Selective Interpretation}

When people receive feedback, there are a number of questions they might ask themselves: Is the feedback valid? Is the source of feedback reliable and trustworthy? What implications does the feedback have in light of what I know about myself? The research literature suggests that people typically answer these questions in ways that promote the survival of their selfviews.

At least three independent investigators have demonstrated that participants will endorse the validity of feedback only if it fits with their self-conceptions (Crary, 1966; Korman, 1968; Markus, 1977). Similarly, Shrauger and Lund (1975) reported that individuals expressed relatively more confidence in the perceptiveness of an evaluator when his or her impression confirmed their self-conceptions. Swann, Griffin, Predmore, and Gaines (1987) replicated this effect and also found that people tended to attribute self-confirmatory feedback to characteris-

\footnotetext{
${ }^{1}$ These data may seem incompatible with Hastie and Kumar's (1979) contention that people are especially likely to recall expectancy-inconsistent evidence. Recent research, however, has suggested that Hastie and Kumar's findings were an artifact of a confound between set size and expectancy. Researchers who have avoided this confound (e.g., Bargh \& Thein, 1985; Hemsley \& Marmurek, 1982) have found that people preferentially recall information that confirms well-formed beliefs (for further details, see Higgins \& Bargh, 1987).
} 
tics of themselves and self-disconfirmatory feedback to the source of the feedback.

Together, the attentional, encoding, retrieval, and interpretational processes described in this section may prove formidable adversaries for self-discrepant feedback. This may be one reason why people's self-conceptions sometimes conflict with the actual appraisals of others (e.g., Felson, 1981a, 1981b) and, more specifically, why people overestimate the extent to which the appraisals of their friends and acquaintances confirm their self-conceptions (Miyamoto \& Dornbusch, 1956; Orpen \& Bush, 1974; Sherwood, 1967; Walhood \& Klopfer, 1971). The fact that these cognitive self-verification strategies can lead to such misconceptions suggests that it is important that they do not work too well, because they may blind targets to perceivers' actual appraisals of them. In fact, if targets' misconceptions are serious enough, perceivers may become sufficiently distraught that they withdraw from the identity negotiation process.

\section{Routine Versus Crisis Self-Verification}

Having read thus far, one might conclude that targets are constantly engaged in active efforts to self-verify; if not carefully selecting friends or displaying identity cues, they might be soliciting self-confirmatory feedback or systematically distorting self-discrepant feedback. Surely, one might protest, people are not constantly preoccupied with verifying their self-conceptions.

I agree. Most of the time, people maintain their self-views without any active or conscious effort. Thus, the bulk of selfverification is done routinely, as part of the normal flow of the identity negotiation process.

\section{Routine Self-Verification}

Most of us spend most of our time with individuals who have implicitly or explicitly agreed to honor the identities we have negotiated with them (e.g., Boissevain, 1974; Goffman, 1959; Swann \& Predmore, 1985). This means that the bulk of the reactions people receive every day will, in a sense, be preprogrammed. Consequently, people will rarely need to demonstrate that they want to be respected or coddled or dominated, because their interaction partners will typically be well aware of this. All they need do is remain in their opportunity structures and their self-views will rarely be challenged.

Because of the automatic nature of such self-verification activities, it is tempting to divorce them from the self and selfverification. For example, once established, it is relatively easy for people to maintain relationships with friends and intimates who routinely provide them with self-confirmatory feedback. Even so, initially they may have selected or "trained" such individuals with an eye to acquiring self-confirmatory feedback. For this reason, it is perfectly appropriate to regard such routine self-verification activities as expressions of the self-concept and the desire to self-verify.

\section{Crisis Self-Verification}

Any event that causes people to question who they are may intensify people's efforts to self-verify (cf. Shibutani, 1961).
Such crisis self-verification activities differ from the relatively automatic, nonreflective activities that characterize routine self-verification in that people are apt to focus attention on themselves and enact specific attempts to elicit self-confirmatory reactions.

Perhaps the most common antecedent of crisis self-verification is the receipt of discrepant feedback. People may respond to such feedback in two ways. First, they may focus attention on the self-conception that has been threatened. Second, they may increase their efforts to learn about themselves by acquiring information that will be highly informative and diagnostic (cf. Swann, Stephenson, \& Pittman, 1981). Because people regard self-confirmatory feedback as particularly diagnostic (Swann \& Read, 1981 a, Investigation 3), such intensified efforts to acquire diagnostic feedback will translate into attempts to acquire self-confirmatory feedback, that is, to self-verify. ${ }^{2}$ In what follows, I present research that shows each of these processes at work.

The tendency for self-discrepant feedback to focus attention onto relevant self-conceptions has been shown by Swann and Hill (1986). Participants who perceived themselves as either emotional or unemotional were given "diagnoses," ostensibly written by student clinicians, indicating that they were either emotional or unemotional. A baseline control group received no feedback. Participants then moved to a different room for a "second experiment." Here the experimenter asked them to decide whether a series of adjectives described them. Some of the adjectives were emotionality related; others were not. As they made each judgment, the experimenter surreptitiously recorded their response latency.

As expected, the results revealed that those who received self-discrepant feedback were faster in making self-descriptive judgments than were those who received either no feedback or self-confirmatory feedback. Furthermore, this pattern of results occurred only for the emotionality-related adjectives; the feedback manipulation had no impact on reaction times to the neutral adjectives. Apparently, self-discrepant feedback induced people to retrieve information relevant to the self-conception from memory, thereby making that information more cognitively available (e.g., Tversky \& Kahneman, 1973).

To the extent that self-discrepant feedback raises the cognitive availability of self-conceptions, it should increase the probability that these self-conceptions guide subsequent behavior (cf. Carver, 1975; Gibbons, 1978; Snyder \& Swann, 1976; Wegner \& Guiliano, 1982). This may explain why participants in the Swann and Hill (1982) and Swann and Read (1981b, Investigation 2) studies discussed earlier were most inclined to behave in a self-confirmatory manner when they were presented with self-discrepant feedback. That is, the self-discrepant feedback may have made their self-conceptions more cognitively available, which in turn increased the probability that they would act on these conceptions by behaving in a manner that would elicit self-confirmatory reactions (cf. Fazio's, 1986, analysis of the conditions under which attitudes guide behavior).

\footnotetext{
${ }^{2}$ Although self-verification is essentially epiphenomenal in such instances, at other times it is theoretically motivated by epistemic or pragmatic considerations.
} 


\section{Antecedents of Crisis Self-Verification}

The impact of self-discrepant feedback may be moderated by the extent to which the recipient of feedback is certain of the relevant self-view. If the recipient of discrepant feedback is uncertain of a self-view, a single dose of discrepant feedback may bring the person to discard that view. If the recipient of discrepant feedback is relatively certain of the self-view, however, that person may work to discredit the feedback. ${ }^{3}$

Among the first to explore the links between self-certainty and self-verification were Maracek and Mettee (1972). These investigators recruited a group of individuals who possessed low self-esteem and who were either low or high in self-certainty. The experimenter provided everyone with success feedback and then monitored their subsequent performance.

There was no evidence of self-verification among individuals who were low in certainty: They always sought to elicit highly positive evaluations by striving to perform well. In contrast, individuals who were high in self-certainty displayed substantial self-verification attempts. Apparently, these individuals regarded their success as a threat to their self-concept and therefore went out of their way to perform poorly, presumably in the service of bolstering their conviction in their own incompetence.

More recent research has offered further evidence of the role of self-certainty in self-verification. For example, Swann and Ely (1984) and Swann, Pelham, and Chidester (in press) have found that people who are high in self-certainty are particularly likely to resist self-discrepant feedback. Perhaps this is one reason why those who are high in self-certainty are more likely to be in relationships with partners who see them as they see themselves (Pelham \& Swann, 1987a; Swann \& Pelham, 1987).

Of course, self-certainty is surely not the only variable that influences how people respond to self-discrepant feedback. Research by Markus (1977), for example, suggests that people will be more inclined to dismiss threats to self-conceptions that they regard as important. From this perspective, certainty and importance may both contribute to the extent to which people strive to verify their self-conceptions, but for different reasons. People may strive to verify highly certain self-conceptions because such conceptions are particularly useful in organizing experience and guiding behavior. At the same time, they may work to verify highly important self-conceptions because they feel that such conceptions are closely related to their goals and future plans (e.g., Pelham \& Swann, 1987b).

Of course, self-discrepant feedback is not the only factor that will initiate crisis self-verification. For instance, people may also experience crisis self-verification when they must make a decision with far-reaching implications (e.g., choosing a career, a marriage partner, or a home). Like discrepant feedback, such decisions focus attention on the self, but on a slightly different aspect of the self. That is, instead of causing people to ask "Who am I?", highly consequential decisions often encourage people to ask "Who am I and what does this suggest for the person I will be?" (cf. Markus \& Nurius, 1986). In many ways, this question highlights one of the self-verifier's greatest struggles, which is reconciling the desire for stable identities with the fact that most of us must assume somewhat different identities over the course of our lives. The conditions under which people negotiate new identities rather than cling to old ones will be considered next.

\section{Self-Verification and Self-Concept Change}

Several theorists (e.g., Gergen, 1977; Tedeschi \& Lindskold, 1976) have recently suggested that our self-conceptions and the identities we negotiate change very rapidly. These authors assume, as I do, that people base their self-conceptions on observations of themselves and the reactions of others. They diverge from my viewpoint, however, in assuming that people place little weight on their personal histories in forming conceptions of self. Their viewpoint therefore suggests that the self is highly malleable, changing with every twitch of the social environment.

Advocates of the malleable-self viewpoint have buttressed their position with the results of laboratory investigations in which people have been shown to change their self-ratings in response to social feedback. Yet such evidence must be treated cautiously. For one thing, outside the laboratory, self-conceptions seem stubbornly resistant to change. Therapists, for example, often fail to alter the self-views of their clients, even after months of intensive therapy. In addition, longitudinal investigations (e.g., Block, 1981; Costa \& McCrae, 1980) have shown that self-conceptions and related psychological structures remain stable over periods as long as 35 years. In light of these and similar data, several reviewers (Shrauger \& Schoeneman, 1979; Wylie, 1979) have concluded that the results of laboratory investigators do not generalize to naturalistic settings.

Such lack of generalizability may stem from the fact that laboratory investigators commonly confront participants with selfdiscrepant feedback and then place them in interpersonal straitjackets. That is, in a typical study, the experimenter presents discrepant feedback to participants and then deprives them of opportunities to resist such feedback, opportunities that they ordinarily enjoy. Perhaps if participants were provided with opportunities to resist self-discrepant feedback, they would do so and consequently display minimal self-rating change.

\section{Self-Generated Stability of Self-Views}

Research by Swann and Hill (1982) supports the notion that unconstrained individuals behave in ways that stabilize their self-views. As mentioned earlier, some targets in this study first received feedback from a confederate that disconfirmed their self-perceived dominance. Then, some targets had an opportunity to interact with the confederate; others received no such opportunity. Afterwards, all targets completed a measure of self-perceived dominance.

Targets in the interaction-opportunity conditions actively sought to undermine the feedback by behaving in a self-confirmatory manner. Furthermore, this opportunity to refute the feedback had important cognitive consequences: Those who had opportunity to interact with the source of the feedback dis-

\footnotetext{
${ }^{3}$ In principle, a person who is extremely high in self-certainty may simply dismiss discrepant feedback out of hand. Thus far, however, we have not encountered participants who are sufficiently certain of their self-views that they were inclined to do this.
} 
played little self-rating change relative to those who were deprived of this opportunity. Therefore, if they could do so, targets actively sought to undermine self-discrepant feedback and consequently displayed little self-rating change.

The results of the Swann and Hill (1982) study suggest that people may change their self-ratings only when they receive selfdiscrepant feedback in highly structured situations in which they are unable to influence or resist the feedback they receive. Furthermore, even when people do receive discrepant feedback in highly structured situations, any changes produced there may be short-lived, because once they leave such situations they may return to self-confirmatory opportunity structures. Here, they will tend to receive feedback that will offset the effects of the self-discrepant feedback.

To test this reasoning, Swann and Predmore (1985) recruited pairs of individuals ("targets" and "intimates") who had been in intimate relationships for an average of 18 months. Some targets had positive self-views; others had negative self-views. Upon their arrival, targets and intimates were separated and intimates reported their perceptions of targets. Although intimates generally tended to see targets as targets saw themselves $(r=.41)$, in some couples the amount of congruency was relatively high (congruent) and in others it was relatively low (incongruent).

After having targets complete a bogus Thematic Apperception Test (TAT), the experimenter ushered them into a room where either their intimate or a complete stranger was waiting. Shortly thereafter, the experimenter returned with the "results" of the TAT and delivered feedback that disconfirmed targets' self-views. The experimenter then left, leaving targets to interact with either their intimate or a stranger for $5 \mathrm{~min}$. At the end of this period the experimenter returned to measure the final selfviews of targets.

The results showed that congruent intimates insulated targets against the self-discrepant feedback, but interacting with a stranger did not. Incongruent intimates had some insulating influence on targets, although not as much as the congruent ones had, presumably because even incongruent intimates had appraisals of targets that were associated with targets' self-views. The really interesting finding, however, was that the congruent intimates of targets with low self-esteem were just as effective in insulating them against positive feedback as the congruent intimates of the targets with high self-esteem were in insulating them against negative feedback! These data therefore suggest that by entering particular social relationships, people enlist "accomplices" who assist them in their self-verification attempts by offering feedback that nullifies self-discrepant feedback. In this way, individuals in the person's opportunity structure may help stabilize their self-conceptions.

Considered together, these data suggest that it is inappropriate to assume that self-conceptions are frightfully frail cognitive structures that change at the drop of the hat. Yet if one accepts the notion that self-conceptions are highly stable, how should one characterize the self-rating changes that people display when they encounter discrepant feedback in laboratory settings? If such changes are not changes in self-conceptions, what are they?

The answer may reside in a consideration of the way selfknowledge is structured. Most self-theorists agree that self- knowledge is organized hierarchically, with global abstractions about the self at the top and highly specific, temporally or situationally bound information at the bottom (e.g., Epstein, 1973; Greenwald, 1981; Markus \& Wurf, 1987; Vallacher \& Wegner, 1985; cf. E. E. Jones \& Gerard's, 1967, analysis of vertical attitude structure). Enduring shifts in self-views occur only when generalized, abstract self-conceptions change. In contrast, transitory fluctuations in self-views occur when specific, concrete self-images change. In some respects, then, a self-conception is analogous to a composite of all the frames in a motion picture film, whereas a self-image is analogous to a single frame in that film (e.g., Turner, 1968).

\section{When Self-Concepts Change}

The foregoing analysis suggests that for enduring changes in self-conceptions to occur, two things must happen. First, people must undergo a major reorganization in the way they view themselves. Second, people's interaction partners must begin providing them with feedback that supports the new self-view. Although the self-verification formulation suggests that both people and their interaction partners tend to resist such changes, this resistance is certainly not insurmountable.

Perhaps the most common chain of events that culminates in enduring self-concept change is for the community to recognize a change in the individual and adjust the way it treats him or her. Such community-initiated changes are usually precipitated by some fairly dramatic change in the individual's age, status, social role, or some combination of these factors. For example, when children become adolescents, when singles get married, or when graduate students become faculty members, they find that people suddenly begin to treat them differently. This causes them to modify their self-conceptions and identity negotiation activities accordingly.

Alternatively, people themselves may sometimes initiate a change in their self-views. For example, people with negative self-views may decide that such views prevent them from attaining some highly desirable goal. They may accordingly approach a therapist for help in modifying the undesirable self-view. A major difficulty that therapists sometimes encounter is that clients inexplicably resist efforts to change the self-view that caused them to seek therapy. Therapists and researchers, however, have begun to develop strategies for dealing with such resistance.

One way to handle resistance is to use it to facilitate the change process, a paradoxical strategy (cf. Watzlawick, Weakland, \& Fisch, 1974). Consider that no matter how extreme people happen to be on a dimension, they are usually somewhat shy of the end point of that dimension. For example, most people with conservative sex role attitudes will feel that they have been misconstrued if someone asks them a question implying that they have extremely conservative attitudes, such as "Why do you think its a good idea to keep women barefoot and pregnant?" In response, they may try to distance themselves from the implications of the question by, for example, pointing out their few relatively liberal beliefs. The paradox is that such identity-protective activities may wind up changing their identities: After espousing relatively liberal beliefs, targets may reflect on 
their behavior and infer that they are actually more liberal than they once thought (e.g., Bem, 1972).

To test this reasoning, Swann, Pelham, and Chidester (in press) asked participants who were high or low in the certainty of their beliefs about sex roles a series of "superattitudinal" leading questions, that is, questions that encouraged them to make statements that were in the direction of but slightly more extreme than their own viewpoints. As Swann and Ely (1984) found, those who were low in belief certainty displayed little resistance to the questions and changed their beliefs accordingly. In contrast, those high in belief certainty displayed considerable resistance to the questions, and as a result of such resistance, they displayed considerable belief change in the opposite direction! A follow-up study replicated the first and showed that paradoxical injunctions change people's positions on belief dimensions rather than merely changing their perception of the dimension. Together, this pair of studies suggests that although it may be very difficult to keep people who are high in belief certainty from resisting discrepant feedback, paradoxical strategies may effectively promote change among such individuals by turning such resistance activities against themselves.

The specific paradoxical strategy used by Swann, Pelham, and Chidester (in press) may be viewed as one of a broad class of strategies in which targets are mislabeled and find that, paradoxically, the only way to reaffirm their initial identity is to distance themselves from a caricature of that identity. One variant of the paradoxical approach was developed by reactance researchers (e.g., Brehm, 1966; Wicklund, 1974). Their approach was to encourage participants to endorse a self-consistent position (as compared with our tack of trying to bring participants to endorse a position that was slightly discrepant from their initial position). The key to the approach was encouraging participants to adopt this position in a manner so heavy-handed that participants' perceptions of autonomy were threatened. They reacted by reasserting their self-conceived autonomy in the only way available, that is, by distancing themselves from their initial position. In a sense, then, reactance processes can be understood as a special case of self-verification in which the threatened self-conception concerns the participant's general sense of autonomy (as opposed to his or her position on a belief dimension).

One general implication of this work is that if change agents use the right strategy, they can even change the self-views of targets who are high in self-certainty. But consider an important caveat. The strategies for changing self-views discussed thus far were designed to produce short-term changes in the self-views of targets. For change to be lasting, the social environment in which that target resides must support the new self-view, and research on selective interaction suggests that people tend to enter relationships with individuals who see them as they see themselves. This means that even if targets are amenable to changing their self-view, the change process may be undermined by the target's friends and intimates (e.g., Swann \& Predmore, 1985).

Imagine, for example, a highly talented person who, for whatever reason (e.g., an abusive parent), has developed a negative view of herself or himself. A therapist may try to deal with this problem by establishing a supportive relationship with the client and encouraging him or her to focus on his or her many talents. Although this technique may produce momentary improvements in the client's self-view, such improvements may be completely undone when the client returns home to a spouse who showers him or her with abuse. Hence, once people establish relationships with partners who see them as they see themselves, these partners tend to reinforce the identities that have been negotiated, even if these identities are negative and at some level the person wishes to overcome them. It would seem then that people with negative self-views sometimes work both to maintain and to improve their self-views, at once pushing and pulling themselves into a standstill. One set of reasons why people might be ambivalent about their identities-the competing motives of self-verification and self-enhancement-will be considered next.

\section{Self-Verification Versus Self-Enhancement}

Surely the most provocative aspect of our findings is that they challenge one of psychology's most widely held theoretical viewpoints, self-enhancement theory (e.g., Baumeister, 1982; Greenwald, 1980; E. E. Jones, 1964; S. C. Jones, 1973; Kaplan, 1975; Taylor \& Brown, in press; Tesser, 1985). This theory assumes that people have a powerful desire for positive feedback and that this desire exerts a potent influence on the identities they negotiate with their interaction partners. ${ }^{4}$

Our findings clearly challenge self-enhancement theory. It is not just that people with negative self-views fail to display the interest in acquiring favorable feedback that self-enhancement theory suggests they should; our findings show that such individuals actually prefer unfavorable to favorable feedback. That is, people with negative self-views seem to prefer and seek out unfavorable feedback (e.g., Swann, Pelham \& Krull, 1987; Swann, Krull, \& Predmore, 1987) and friends and intimates who think poorly of them (e.g., Pelham \& Swann, 1987b; Swann \& Pelham, 1987; Swann \& Predmore, 1985). People with negative self-conceptions also adopt interaction strategies that tend to elicit unfavorable reactions, especially when they suspect that their partners view them positively (Swann \& Read, 1981 b, Study 2). Furthermore, should they somehow manage to elicit positive reactions, they may still maintain their selfviews by failing to attend to and remember such reactions (Swann \& Read, 1981a, Studies 1 and 3) or by dismissing such reactions as inaccurate (Swann, Griffin, Predmore, \& Gaines, 1987).

Critics will surely counter such contentions by pointing to the large amount of evidence that seems to support self-

\footnotetext{
${ }^{4}$ I refer to the weak form of self-enhancement theory here (which suggests that people with low and high self-esteem should be equally enamored with favorable feedback) instead of the strong form (which argues that people with low esteem should be more enamored with favorable feedback than should people with high esteem) because there is little sound support for the strong form. That is, most studies that have been taken as support for the strong form of self-enhancement are flawed (e.g., researchers generally manipulated rather than measured self-esteem). Moreover, recent research has consistently failed to support the strong form of the theory (e.g., Alloy \& Abramson, 1979; Brown, 1986; Camphell, 1986; and the research reviewed in this article).
} 
enhancement theory (for reviews, see S. C. Jones, 1973; Shrauger, 1975). I suggest, however, that many alleged "selfenhancement effects" are actually self-verification effects in disguise. One reason for this is that most people develop highly positive conceptions of themselves.

\section{The Ubiquity of Positive Self-Conceptions}

My argument begins with some observations of the socialization process. As a rule, caretakers in our society are incredibly supportive of children, heaping on positive feedback at every turn (e.g., Fagot, 1978). Children, being rather naive in such matters, generally take such feedback to heart and develop remarkably positive self-views. They may then use these idealized conceptions of themselves to guide their subsequent behavioral and cognitive activities and gradually "edit" these conceptions as they acquire additional evidence (Turner, 1968).

Although this editing process will generally promote more realistic self-views, several factors may lead people to maintain highly positive views of themselves. Caretakers, for example, may continue to be generous with positive feedback. In addition, children themselves may strive to be the wonderful human beings that their parents believe them to be by working to develop their strengths and avoiding contexts in which their weaknesses might become apparent.

Even people who fail to excell may encounter negative feedback only rarely. Blumberg (1972) and Tesser and Rosen (1975), for example, have shown that there exist social norms that discourage people from delivering direct negative feedback to others. So powerful are such norms that it is often impossible to tell that people dislike their interaction partners by listening to what they say to them. Only by looking at the paralinguistic content of their utterances (e.g., timing of utterances, tone of voice, etc.) is it sometimes possible to identify individuals who dislike their partners (e.g., DePaulo, Stone, \& Lassiter, 1985; Mehrabian, 1972).

In short, people rarely develop self-views that are generally negative (e.g., Pelham \& Swann, 1987b) because their social worlds rarely provide them with feedback that would sustain such views. This has several implications for assessing the relative merits of the self-enhancement and self-verification formulations. For example, the tendency for people with positive selfconcepts to be overrepresented in most samples means that it is futile to try to identify individuals who are low in self-esteem by using median split techniques (as many past researchers have done). We have found that to identify people who are truly low in self-esteem (i.e., who believe that they are below average), one must generally select individuals who score in the lower $10 \%$ to $30 \%$ of college student samples. This is not a minor methodological quibble; unless people designated as low in self-esteem are truly low in self-esteem, it is possible to mistake self-verification effects for self-enhancement effects. If, for example, individuals with high self-esteem are misclassified as having low self-esteem, it may appear that people with low self-esteem sought favorable feedback or resisted unfavorable feedback when, in reality, those with high self-esteem were responsible for such activity.

In addition, if most people have positive self-views, attempting to manipulate self-esteem by providing people with a dose or two of negative feedback (as many researchers have done) is not a viable way to compare the relative importance of selfverification and self-enhancement tendencies. Self-verification processes are presumably motivated by psychological investment borne out of considerable experience. Given that most people possess relatively positive self-views, presenting unfavorable feedback to unselected individuals might be likely to motivate them to verify their positive self-views (e.g., Swann $\&$ Read, $1981 \mathrm{~b})$; at any rate, it should not cause them to work to confirm negative self-views. The only individuals who should reliably work to verify their negative self-views are those who possess chronically negative self-views of which they are reasonably certain.

\section{The Cognitive-Affective Crossfire}

Lest I appear determined to reduce all self-enhancement effects to the status of epiphenomena or methodological artifacts, let me add an important caveat: Affective reactions to feedback generally conform to self-enhancement theory, and cognitive responses generally conform to self-verification theory (e.g., Shrauger, 1975). For example, Swann, Griffin, Predmore, and Gaines (1987) presented individuals who possessed either positive or negative self-concepts with either favorable or unfavorable social feedback. As the self-verification formulation would suggest, participants with negative self-concepts indicated that unfavorable feedback was more self-descriptive than favorable feedback. As self-enhancement theory would suggest, however, those who received unfavorable feedback were considerably more depressed, anxious, and hostile than were those who received favorable feedback. Swann, Krull, and Predmore (1987) provided further support for the independence of cognitive and affective responses. They found that the tendency for people with low self-esteem to actively solicit unfavorable feedback was independent of the negative affect introduced by previous doses of unfavorable feedback.

This research suggests that people who are low in self-esteem may be caught in a crossfire between their cognitions and affects: Even though they value unfavorable feedback on a cognitive level because of its apparent accuracy, they find it affectively abhorrent because of its damning implications. How then, should one answer the question "What do people with low self-esteem really want?" Part of the answer obviously depends on what one means by the word want. Evidence that people with low self-esteem seek unfavorable feedback (Swann, Krull, \& Predmore, 1987; Swann \& Read, 1981b, Study 1) obviously suggests that they want it in some sense of the word. Nevertheless, the fact that unfavorable feedback makes people miserable suggests that they would avoid it if possible.

Semantics aside, the real difficulty here may be that the question "What do people with low self-esteem really want?" is based on an erroneous assumption, the assumption of psychological unity. This assumption holds that a superordinate cognitive system directs all mental activity and resolves inconsistencies between thoughts, feelings, and actions. Several aspects of the Swann, Griffin, Predmore, and Gaines (1987) findings contradict the unity assumption. Most important, the overall pattern of data indicated that cognitive responses were based on the subjective veridicality of the stimuli, such as the extent to 
which the feedback was consistent with the person's self-views, and affective responses were based simply on whether the feedback was negative or positive.

What might account for this independence of cognitive and affective responses? Recent work by dual and multiple systems theorists (e.g., Epstein, 1984; Gazzaniga, 1985; Tomkins, 1981; T. D. Wilson, 1985; Zajonc, 1980, 1984) may be relevant here. This work suggests that the cognitive and affective systems perform very different tasks. The cognitive system seeks, classifies, and analyzes information in an attempt to maximize the subjective veridicality of the products of these operations. For example, when social feedback is received, it is first identified and then compared to information about the self stored in memory. If the feedback concurs with the information in memory (i.e., appears veridical), it is accepted and integrated with past knowledge.

The affective system, in contrast, enables the organism to respond quickly to events that pose an immediate threat to personal safety. This relatively primitive system apparently reacts on the basis of relatively gross discriminations (i.e., threatening vs. not threatening, favorable to self vs. unfavorable to self) and little or no analysis of the subjective veridicality of the stimuli. This system, then, trades precision for speed. It may not perform a highly sophisticated analysis of stimuli, but it reacts quickly.

Of course, believing that the affective system produces selfenhancement effects and the cognitive system independently produces self-verification effects still leaves many questions unanswered. For example, as there is obviously some interaction between the two systems, what is the nature of such interaction?

\section{Eluding - and Failing to Elude-the Crossfire}

Recent research by Swann, Pelham, and Krull (1987) offers some insight into how the cognitive and affective systems interact. Their central thesis was that people are motivated to avert conflicts between their cognitively based desire for self-verification and their affectively based desire for self-enhancement. Toward this end, people seek feedback that is both self-verifying and self-enhancing. They first showed that people's self-concepts are sufficiently differentiated that even those with very low global self-esteem (lowest $10 \%$ ) believe that they possess a ray of hope, that is, a positive attribute that might serve as a source of pride and inspiration. They then asked if even people with globally negative self-views would seek verification for their positive attributes. They found that when people's informationseeking activities were relatively unconstrained, there was a tendency for them to sample feedback that would verify their positive attributes; when they were constrained to sample feedback pertaining to their negative attributes, however, people solicited unfavorable rather than favorable feedback. Moreover, people with low and high self-esteem were equally inclined to display this pattern of feedback seeking.

One implication of Swann, Pelham, and Krull's (1987) findings is that researchers should use measures of specific self-conceptions instead of or in addition to global measures of the selfconcept. More generally, their data suggest that when they can, people try to avoid getting into cognitive-affective crossfires by striving to verify their positive attributes. Apparently, people want to know the truth about themselves, but there are many truths, and the truth people desire the most is the one that offers a ray of hope.

Although people may avoid crossfires when they can, it is important to remember that there are times when it is impossible to avoid such crossfires. In selecting a friend or intimate, for example, people with one or more negative self-conceptions may discover that it is impossible to locate someone who will verify both their positive and their negative attributes because halo biases (e.g., Chapman \& Chapman, 1969; Hamilton \& Gifford, 1976) tend to homogenize people's appraisals of one another. This means that sometimes individuals may be forced to choose between partners who are uniformly positive or uniformly negative toward them, a choice that places them in the middle of the cognitive-affective crossfire they wish to avoid.

How do people with negative self-views resolve this crossfire? It appears that they choose partners who have unfavorable appraisals of them. Swann and Pelham (1987), for example, found that people with negative as opposed to positive self-conceptions indicated that ideally, their friends and intimates should perceive them relatively unfavorably. Furthermore, a follow-up study indicated that roommates who possessed negative selfviews planned to flee from relationships in which they were perceived favorably and remain in relationships in which they were perceived unfavorably!

At first blush, the results of the Swann and Pelham (1987) studies may seem to fly in the face of evidence indicating that even people with low self-esteem are more attracted to evaluators who have favorable appraisals of them (for recent reviews, see Berscheid, 1985; Huston \& Levinger, 1978; S. C. Jones, 1973; Mettee \& Aronson, 1974; Reis, 1985). Virtually all of the evidence suggesting that positivity is prepotent over congruency, however, has come from laboratory investigations in which participants' responses had few consequences. Clearly, it is one thing to express attraction for someone who seems to have an inappropriately favorable appraisal of oneself; it is quite another to pursue a relationship with such an individual (cf. Huston \& Levinger, 1978), as doing so may bring on the undesired epistemic and pragmatic consequences associated with discrepant feedback.

It appears, then, that if people are forced into a crossfire between self-verification and self-enhancement, they will self-enhance only if they can avoid the aversive epistemic and pragmatic consequences associated with failure to self-verify (cf. Schlenker, 1980). In instances in which people must either selfverify or self-enhance, they will self-verify.

\section{Summary and Implications}

The basic argument here is that people are highly motivated to verify their self-conceptions, and this motivation shapes the nature of the identity negotiation process. Some strategies of self-verification are interpersonal, involving people's efforts to bring others to see them as they see themselves. Other strategies are intrapsychic, involving processes through which people see more self-confirmatory evidence than actually exists. Orthogonal to this distinction, some strategies are relatively automatic and effortless and others are conscious and effortful.

Although self-verification processes ordinarily tend to stabi- 
lize people's conceptions of themselves, under certain specifiable conditions they can actually be used to promote self-concept change. Self-concept change may be particularly desirable when people have negative self-conceptions, because such individuals are trapped in a crossfire between a cognitively based desire for self-verification and an affectively based desire for self-enhancement. Although people generally strive to avoid crossfires, at times they are unavoidable. When caught in such situations, people resolve them in favor of self-verification.

In emphasizing the contribution of targets to the process of identity negotiation, I do not wish to minimize the contribution of perceivers to this process. In fact, my use of the term identity negotiation in the title and throughout this article was intended to encourage researchers to consider simultaneously how the activities of both perceivers and targets are woven into the fabric of social interaction.

The concept of identity negotiation is based on the assumption that people enter their social interactions with certain goals in mind and try to establish mutual identities that enable them to attain these goals. A process of negotiation ensues and, if successful, a working consensus emerges that defines the identity that each person is to assume during the interaction. From then on, the interaction proceeds smoothly until the participants have achieved their goals or one partner decides not to honor the identity that he or she has negotiated (e.g., Goffman, 1959; McCall \& Simmons, 1966; Stryker \& Statham, 1985; Weinstein \& Deutschberger, 1963).

A major advantage of the identity negotiation framework is that it explicitly acknowledges the influence of both personal characteristics (e.g., goals, agendas, and life histories) and social structural variables (e.g., norms, roles, and social conventions) on the nature and outcome of social interaction. This relatively expansive perspective may lead to insights that could not be reached from either a personological or a social perspective alone.

A case in point is the debate between advocates of self-enhancement and advocates of self-verification. Over the last three decades, dozens of psychologists have tested the hypothesis that people with negative self-conceptions are inclined to embrace unfavorable feedback. A common tactic has been to "lower people's self-conceptions" by providing them with negative feedback and to then observe their reactions to feedback. This approach ignores the fact that the vast majority of people enter the laboratory with well-articulated views of themselves: views that are liable to exert far more influence on reactions to unfavorable feedback than anything an experimenter could ethically do to them. In such instances the most appropriate research strategy is one based on an individual differences approach, that is, one that involves measuring rather than manipulating people's self-views.

Other research, such as work on the stability of self-conceptions, can benefit from a more social perspective. For example, many researchers have attempted to explain the tendency for people to maintain stable conceptions of themselves by referring to various biases in information processing. Although such biases are surely important, exclusive emphasis on such intrapsychic sources of stability in people's self-views leads researchers to overlook the contribution of people's social environments to the stability of their self-conceptions. That is, as the research in this article suggests, people may stabilize their self-conceptions by creating around themselves social environments that provide them with support for their self-conceptions. The stability inherent in these environments will in turn stabilize their self-views.

These are but two examples of the insights that can be gained from adopting an identity negotiation framework, a framework that embraces both personological and social influences on human behavior. Admittedly, one disadvantage associated with an identity negotiation framework is that it is inherently more complex than considering characteristics of people or of situations independently. Yet I believe that the benefits to be gained from this approach far outweigh the costs. In fact, it is difficult to imagine how we can ever attain a full understanding of either other-perception or self-perception without understanding the process of identity negotiation, as this process may well be the major mechanism through which we come to understand ourselves and those around us.

\section{References}

Alloy, L. B., \& Abramson, L. Y. (1979). Judgments of contingency in depressed and non-depressed students: Sadder but wiser? Journal of Experimental Psychology: General, 108, 441-485.

Athay, M., \& Darley, J. M. (1981). Toward an interaction centered theory of personality. In N. Cantor \& J. F. Kihlstrom (Eds.), Personality, cognition, and social interaction (pp. 281-308). Hillsdale, NJ: Erlbaum.

Backman, C. W., \& Secord, P. F. (1962). Liking, selective interaction, and misperception in congruent interpersonal relations. Sociometry, 25, 321-335.

Bargh, J. A., \& Thein, R. D. (1985). Individual construct accessibility, person memory and the recall-judgment link: The case of information overload. Journal of Personality and Social Psychology, 49, 1129-1146.

Baumeister, R. F. (1982). A self-presentational view of social phenomena. Psychological Bulletin, 91, 3-26.

Baumgardner, A. H., \& Brownlee, E. A. (1987). Strategic failure in social interaction: Evidence for expectancy disconfirmation processes. Journal of Personality and Social Psychology, 52, 525-535.

Bem, D. J. (1972). Self-perception theory. In L. Berkowitz (Ed.), Advances in experimental social psychology (Vol. 6, pp. 1-62). New York: Academic Press.

Berscheid, E. (1985). Interpersonal attraction. In G. Lindzey \& E. Aronson (Eds), Handbook of social psychology (Vol. 2, pp. 413-484). New York: Random House.

Block, J. (1981). Some enduring and consequential structures of personality. In A. I. Rabin et al. (Eds.), Further explorations in personality (pp. 27-43). New York: Wiley.

Blumberg, H. H. (1972). Communication of interpersonal evaluations. Journal of Personality and Social Psychology, 23, 157-162.

Boissevain, J. (1974). Friends of friends: Networks, manipulators and coalitions. Oxford, England: Blackwell.

Brehm, J. W. (1966). A theory of psychological reactance. New York: Academic Press.

Brown, J. D. (1986). Evaluations of self and others: Self-enhancement biases in social judgment. Social Cognition, 4, 353-376.

Broxton, J. A. (1963). A test of interpersonal attraction predictions derived from balance theory. Journal of Abnormal and Social Psychology, 66, 394-397.

Bruner, J. S., Goodnow, J. J., \& Austin, G. A. (1956). A study of thinking. New York: Wiley.

Campbell, J. D. (1986). Similarity and uniqueness: The effects of attri- 
bute type, relevance, and individual differences in self-esteem and depression. Journal of Personality and Social Psychology, 50, 281294.

Carson, R. C. (1969). Interaction concepts of personality. Chicago: Aldine.

Carver, C. S. (1975). Physical aggression and function of objective selfawareness and attitudes toward punishment. Journal of Experimental Social Psychology, 11, 510-519.

Chapman, L. J., \& Chapman, J. P. (1969). Illusory correlation as an obstacle to the use of valid psychodiagnostic signs. Journal of Abnormal Psychology, 74, 271-280.

Clarke, G. L. (1954). Elements of ecology. New York: Wiley.

Cooley, C. S. (1902). Human nature and the social order. New York: Scribner's.

Costa, B. T., Jr., \& McCrae, R. R. (1980). Still stable after all these years: Personality as a key to some issues in adulthood and old age. In P. B. Baltes \& O. G. Brim (Eds.), Life span development and behavior (Vol. 3, pp. 5-102). New York: Academic Press.

Crary, W. G. (1966). Reactions to incongruent self-experiences. Journal of Consulting Psychology, 30, 246-252.

Darley, J. M., \& Fazio, R. H. (1980). Expectancy confirmation processes arising in the interaction sequence. American Psychologist, 35 , 867-881.

DePaulo, B. M., Stone, J. I., \& Lassiter, G. D. (1985). Deceiving and detecting deceit. In B. R. Schlenker (Ed.), Self and social life (pp. 323-370). New York: McGraw-Hill.

Epstein, S. (1973). The self-concept revisited: On a theory of a theory. American Psychologist, 28, 404-416.

Epstein, S. (1984). The self-concept: A review and proposal of an integrated theory of personality. In E. Staub (Ed.), Personality: Basic issues and current research (pp. 81-132). Englewood Cliffs, NJ: Prentice-Hall.

Fagot, B. I. (1978). The influence of child on parental reactions to toddler children. Child Development, 49, 459-465.

Fazio, R. H. (1986). How do attitudes guide behavior. In R. M. Sorrentino \& E. Tory Higgins (Eds.), Motivation and cognition: Foundations of social behavior (pp. 204-243). New York: Guilford Press.

Felson, R. B. (198 Ia). Self and reflected appraisal among football players. Social Psychology Quarterly, 44, 116-126.

Felson, R. B. (1981b). Social sources of information in the development of the self. Sociological Quarterly, 22, 69-79.

Gazzaniga, M. S. (1985). The social brain. New York: Basic Books.

Gergen, K. J. (1977). The social construction of self-knowledge. In T. Mischel (Ed.), The self: Psychological and philosophical issues (pp. 139-169). Totowa, NJ: Rowman and Littlefield.

Gibbons, F. X. (1978). Sexual standards and reaction to pornography: Enhancing behavioral consistency through self-focused attention. Journal of Personality and Social Psychology, 36, 976-987.

Goffman, E. (1959). The presentation of self in everyday life. New York: Anchor Books.

Greenwald, A. G. (1980). The totalitarian ego: Fabrication and revision of personal history. American Psychologist, 35, 603-618.

Greenwald, A. G. (1981). Self and memory. In G. H. Bower (Ed.), Psychology of learning and motivation (Vol. 15, pp. 201-236). New York: Academic Press.

Hamilton, D. L., \& Gifford, R. K. (1976). Illusory correlation in interpersonal perception: A cognitive basis of stereotypic judgments. Journal of Experimental Social Psychology, 12, 392-407.

Harvey, O. J., Hunt, D. E., \& Schroder, H. M. (1961). Conceptual systems and personality organization. New York: Wiley.

Hastie, R., \& Kumar, P. (1979). Person memory: Personality traits as organizing principles in memory for behaviors. Journal of Personality and Social Psychology, 37, 25-38.

Hemsley, G. D., \& Marmurek, H. C. (1982). Person memory: The pro- cessing of consistent and inconsistent person information. Personality and Social Psychology Bulletin, 8, 433-438.

Higgins, E. T., \& Bargh, J. A. (1987). Social cognition and social perception. In M. R. Rosenzweig \& L. W. Porter (Eds.), Annual review of psychology (Vol. 38, pp. 369-425). Palo Alto, CA: Annual Reviews.

Hilton, J. L., \& Darley, J. M. (1985). Constructing other persons: A limit on the effect. Journal of Experimental Social Psychology, 21, 118.

Huston, T. L., \& Levinger, G. (1978). Interpersonal attraction and relationships. In M. R. Rosenzweig \& L. W. Porter (Eds.), Annual review of psychology (Vol. 29, pp. 115-156). Palo Alto, CA: Annual Reviews.

Jones, E. E. (1964). Ingratiation. New York: Appleton-Century-Crofts.

Jones, E. E. (1986). Interpreting interpersonal behavior: The effects of expectancies. Science, 234, 41-46.

Jones, E. E., \& Gerard, H. B. (1967). Foundations of social psychology. New York: Wiley.

Jones, S. C. (1973). Self and interpersonal evaluations: Esteem theories versus consistency theories. Psychological Bulletin, 79, 185-199.

Jones, S. C., \& Panitch, D. (1971). The self-fulfilling prophecy and interpersonal attraction. Journal of Experimental Social Psychology, 7, 356-366.

Kaplan, H. B. (1975). Prevalence to the self-esteem motive. In H. B. Kaplan (Ed.), Self-attitudes and deviant behavior (pp. 16-27). Pacific Palisades, CA: Goodyear.

Kelley, H. H., \& Stahelski, A. J. (1970). The social interaction basis of cooperators' and competitors' beliefs about others. Journal of Personality and Social Psychology, 16.66-91.

Kihlstrom, J. F., \& Cantor, N. (1984). Mental representations of the self. In L. Berkowitz (Ed.), Advances in experimental social psychology (Vol. 12, pp. 1-47). New York: Academic Press.

Klayman, J., \& Ha, Y.-W. (1987). Confirmation, disconfirmation, and information in hypothesis testing. Psychological Review, 94, 211 228.

Korman, A. K. (1968). Task success, task popularity, and self-esteem as influences on task liking. Journal of Applied Psychology, 52, 484-490.

Lecky, P. (1945). Self-consistency: A theory of personality. New York: Island Press.

Maracek, J., \& Mettee, D. R. (1972). Avoidance of continued success as a function of self-esteem, level of esteem certainty, and responsibility for success. Journal of Personality and Social Psychology, 22, 90107.

Markus, H. (1977). Self-schemas and processing information about the self. Journal of Personality and Social Psychology, 35, 63-78.

Markus, H., \& Nurius, P. (1986). Possible selves. American Psychologist, 41, 954-969.

Markus, H., \& Wurf, E. (1987). The dynamic self-concept: A social psychological perspective. In M. R. Rosenzweig \& L. W. Porter (Eds.), Annual review of psychology (Vol. 38, pp. 299-337). Palo Alto, CA: Annual Reviews.

McCall, G. J., \& Simmons, J. L. (1966). Identities and interactions: An examination of human associations in everyday life. New York: Free Press.

Mead, G. H. (1934). Mind, self and society. Chicago: University of Chicago Press.

Mehrabian, A. (1972). Nonverbal communication. Chicago: Aldine.

Mettee, D. R., \& Aronson, E. (1974). Affective reactions to appraisal from others. In T. L. Huston (Ed.), Foundations of Interpersonal Attraction. New York: Academic Press.

Miller, D. T., \& Turnbull, W. (1986). Expectancies and interpersonal processes. In M. R. Rosenzweig and L. W. Porter (Eds.), Annual review of psychology (Vol. 37, pp. 233-256). Palo Alto, CA: Annual Reviews.

Miyamoto, S. F., \& Dornbusch, S. A. (1956). Test of the symbolic inter- 
actionist hypothesis of self-conception. American Journal of Sociology, 61, 399-403.

Newcomb, T. M. (1956). The prediction of interpersonal attraction. American Psychologist, 11, 575-586.

Odum, E. P. (1963). Ecology, New York: Holt, Rhinehart, and Winston. Orpen, C., \& Bush, R. (1974). The lack of congruence between selfconcept and public image. Journal of Social Psychology, 93, 145-146.

Pelham, B., \& Swann, W. B., Jr. (1987a). Accuracy in friendship relationships. Unpublished manuscript, University of Texas at Austin.

Pelham, B., \& Swann, W. B., Jr. (1987b). Self-esteem: Components and consequences. Unpublished manuscript, University of Texas at Austin.

Pervin, L. A., \& Rubin, D. B. (1967). Student dissatisfaction with college and the college dropout: A transactional approach. Journal of Social Psychology, 72, 285-295.

Reis, H. T. (1985). The role of the self in the imitation and course of social interaction. In W. Ickes (Ed.), Compatible and incompatible relationships (pp. 209-231). New York: Springer-Verlag.

Rosenthal, R., \& Jacobson, L. (1968). Pygmalion in the classroom: Teacher expectations and pupils' intellectual development. New York: Holt, Rinehart \& Winston.

Schlenker, B. R. (1980). Impression management. Belmont, CA: Wadsworth.

Secord, P. F., \& Backman, C. W. (1965). An interpersonal approach to personality. In B. Maher (Ed.), Progress in experimental personality research (Vol. 2, pp. 91-125). New York: Academic Press.

Sherwood, J. J. (1967). Self-identity and referent others. Sociometry, 30, 404-409.

Shibutani, T. (1961). Society and personality: An interactionist approach to social psychology. Englewood Cliffs, NJ: Prentice-Hall.

Shrauger, J. S. (1975). Responses to evaluation as a function of initial self-perceptions. Psychological Bulletin, 82, 581-596.

Shrauger, J. S., \& Lund, A. (1975). Self-evaluation and reactions to evaluations from others. Journal of Personality, 43, 94-108.

Shrauger, J. S., \& Schoeneman, T. J. (1979). Symbolic interactionist view of self-concept: Through the looking glass darkly. Psychological Bulletin, 86, 549-573.

Silverman, J. (1964). Self-esteem and differential responsiveness to success and failure. Journal of Social Psychology, 69, 115-119.

Snyder, M. (1984). When belief creates reality. In L. Berkowitz (Ed.), Advances in experimental social psychology (Vol. 16, pp. 248-305). New York: Academic Press.

Snyder, M., \& Swann, W. B., Jr. (1976). When actions reflect attitudes: The politics of impression management. Journal of Personality and Social Psychology, 34, 1034-1042.

Snyder, M., \& Swann, W. B., Jr. (1978a). Behavioral confirmation in social interaction: From social perception to social reality. Journal of Experimental Social Psychology, 14, 148-162.

Snyder, M., \& Swann, W. B., Jr. (1978b). Hypothesis testing processes in social interaction. Journal of Personality and Social Psychology, $36,1202-1212$.

Stryker, S., \& Statham, A. (1985). Symbolic interaction and role theory. In G. Lindzey \& E. Aronson (Eds.), Handbook of social psychology (Vol. 2, pp. 31 1-378). Hillsdale, NJ: Random House.

Swann, W. B., Jr. (1983). Self-verification: Bringing social reality into harmony with the self. In J. Suls \& A. G. Greenwald (Eds.), Social psychological perspectives on the self (Vol. 2, pp. 33-66). Hillsdale, NJ: Erlbaum.

Swann, W. B., Jr. (1984). Quest for accuracy in person perception: A matter of pragmatics. Psychological Review, 91, 457-477.

Swann, W. B., Jr. (1985). The self as architect of social reality. In B. Schlenker (Ed.), The self and social life (pp. 100-125). New York: McGraw-Hill.

Swann, W. B., Jr., \& Ely, R. J. (1984). A battle of wills: Self-verification versus behavioral confirmation. Journal of Personality and Social Psychology, 46, 1287-1302.

Swann, W. B., Jr., \& Giuliano, T. (in press). Confirmatory search strategies in social interaction: When, how, why, and with what consequences. Journal of Social and Clinical Psychology.

Swann, W. B., Jr., Griffin, J. J., Jr., Predmore, S. C., \& Gaines, B. (1987). Cognitive-affective crossfire: When self-consistency meets self-enhancement. Journal of Personality and Social Psychology, 52, 881889.

Swann, W. B., Jr., \& Hill, C. A. (1982). When our identities are mistaken: Reaftirming self-conceptions through social interaction. Journal of Personality and Social Psychology, 43, 59-66.

Swann, W. B., Jr., and Hill, C. A. (1986). Some cognitive consequences of threats to the self. Unpublished data, University of Texas at Austin.

Swann, W. B., Jr., Krull, D. S., \& Predmore, S. C. (1987). Seeking truth and reaping despair: Self-verification among people with negative selfviews. Manuscript submitted for publication.

Swann, W. B., Jr., \& Pelham, B. W. (1987). The social construction of identity: Self-verification through friend and intimate selection. Manuscript submitted for publication.

Swann, W. B., Jr., Pelham, B. W., \& Chidester, T. R. (in press). Change through paradox: Using self-verification to alter beliefs. Journal of Personality and Social Psychology.

Swann, W. B., Jr., Pelham, B. W., \& Krull, D. S. (1987). The ray of hope: Averting the conflict by avoiding the choice. Manuscript submitted for publication.

Swann, W. B., Jr., \& Predmore, S. C. (1985). Intimates as agents of social support: Sources of consolation or despair? Journal of Personality and Social Psychology, 49, 1609-1617.

Swann, W. B., Jr., \& Read, S. J. (1981a). Acquiring self-knowledge: The search for feedback that fits. Journal of Personality and Social Psychology, 41, 1119-1128.

Swann, W. B., Jr., \& Read, S. J. (1981b). Self-verification processes: How we sustain our self-conceptions. Journal of Experimental Social Psychology, 17, 351-372.

Swann, W. B., Jr., \& Snyder, M. (1980). On translating beliefs into action: Theories of ability and their application in an instructional setting. Journal of Personality and Social Psychology, 38, 879-888.

Swann, W. B., Jr., Stephenson, B., \& Pittman, T. S. (1981). Curiosity and control: On the determinants of the search for social knowledge. Journal of Personality and Social Psychology, 40. 635-642.

Taylor, S. E., \& Brown, J. D. (in press). Illusion and well being: Some social psychological contributions to a theory of mental health. Psychological Bulletin.

Tedeschi, J. T., \& Lindskold, S. (1976). Social psychology: Interdependence, interaction, and influence. New York: Wiley.

Tesser, A. (1985, August). Toward a self-evaluation maintenance model of social behavior. Paper presented at the annual convention of the American Psychological Association, Los Angeles.

Tesser, A., \& Rosen, S. (1975). The reluctance to transmit bad news. In L. Berkowitz (Ed.), Advances in experimental social psychology (Vol. 8, pp. 192-232). New York: Academic Press.

Tomkins, S. S. (1981). The quest for primary motives: Biography and autobiography of an idea. Journal of Personality and Social Psychology, 41, 306-329.

Turner, R. H. (1968). The self-conception in social interaction. In C. Gordon \& K. G. Gergen (Eds.), The self in social interaction (pp. 93106). New York: Wiley.

Tversky, A., \& Kahneman, D. (1973). Availability: A heuristic for judging frequency and probability. Cognitive Psychology, 5, 207-232.

Vallacher, R. R., \& Wegner, D. M. (1985). Action identification theory. Hillsdale, NJ: Erlbaum.

Walhood, D. S., \& Klopfer, W. G. (1971). Congruence between self- 
concept and public image. Journal of Consulting and Clinical Psychology, 37, 148-150.

Wason, P. C., \& Johnson-Laird, P. N. (1972). Psychology of reasoning: Structure and content. London: D. T. Batsford.

Watzlawick, P., Weakland, J. H., \& Fisch, R. (1974). Change: Principles of problem formation and problem resolution. New York: Norton.

Wegner, D. M., \& Guiliano, T. (1982). The forms of social awareness. In W. J. Ickes \& E. S. Knowles (Eds.), Personality, roles, and social behavior. New York: Springer-Verlag.

Weinstein, E., \& Deutschberger, P. (1963). Some dimensions of altercasting. Sociometry, 26, 454-466.

Wicklund, R. A. (1974). Freedom and reactance. Potomac, MD: Erlbaum.

Wilson, E. O. (1974). Sociobiology: The new synthesis. Cambridge: Harvard University Press.

Wilson, T. D. (1985). Strangers to ourselves: The origins and accuracy of beliefs about one's own mental states. In J. H. Harvey \& G. Weary
(Eds.), Attribution in contemporary psychology (pp. 9-36). New York: Academic Press.

Word, C. O., Zanna, M. P., \& Cooper, J. (1974). The nonverbal mediation of self-fulfilling prophecy effects in interracial interaction. Journal of Experimental Social Psychology, 10, 109-120.

Wylie, R. (1979). The self concept. Lincoln: University of Nebraska Press.

Zajonc, R. B. (1980). Feeling and thinking: Preferences need no inferences. American Psychologist, 35, 151-175.

Zajonc, R. B. (1984). On the primacy of affect. American Psychologist, $39,117-123$.

Zanna, M. P., \& Pack, S. J. (1975). On the self-fulfilling nature of apparent sex differences in behavior. Journal of Experimental Social Psychology, 11, 583-591.

Received December 1, 1986

Revision received July 1, 1987

Accepted April 30, 1987

\section{Instructions to Authors}

Authors should prepare manuscripts according to the Publication Manual of the American Psychological Association (3rd ed.). Articles not prepared according to the guidelines of the Man$\mathrm{ual}$ will not be reviewed. All manuscripts must include an abstract of 100-150 words typed on a separate sheet of paper. Typing instructions (all copy must be double-spaced) and instructions on preparing tables, figures, references, metrics, and abstracts appear in the Manual. Also, all manuscripts are subject to editing for sexist language.

APA policy prohibits an author from submitting the same manuscript for concurrent consideration by two or more journals. APA policy also prohibits duplicate publication, that is, publication of a manuscript that has already been published in whole or in substantial part in another journal. Prior and duplicate publication constitutes unethical behavior, and authors have an obligation to consult journal editors if there is any chance or question that the paper might not be suitable for publication in an APA journal. Also, authors of manuscripts submitted to APA journals are expected to have available their raw data throughout the editorial review process and for at least 5 years after the date of publication. For further information on content, authors should refer to the editorial in the March 1979 issue of this journal (Vol. 37, No. 3, pp. 468-469).

The reference citation for any article in any JPSP section follows APA's standard reference style for journal articles; that is, authors, year of publication, article title, journal title, volume number, and page numbers. The citation does not include the section title.

Authors will be required to state in writing that they have complied with APA ethical standards in the treatment of their sample, human or animal, or to describe the details of treatment. A copy of the APA Ethical Principles may be obtained from the APA Ethics Office, 1200 17th Street, N.W., Washington, DC 20036.

Anonymous reviews are optional, and authors who wish anonymous reviews must specifically request them when submitting their manuscripts. Each copy of a manuscript to be anonymously reviewed should include a separate title page with authors' names and affiliations, and these should not appear anywhere else on the manuscript. Footnotes that identify the authors should be typed on a separate page. Authors should make every effort to see that the manuscript itself contains no clues to their identities.

Manuscripts should be submitted in quadruplicate, and all copies should be clear, readable, and on paper of good quality. A dot matrix or unusual typeface is acceptable only if it is clear and legible. Dittoed and mimeographed copies will not be considered. Authors should keep a copy of the manuscript to guard against loss. Mail manuscripts to the appropriate section editor. Editors' addresses appear on the inside front cover of the journal.

Section editors reserve the right to redirect papers among themselves as appropriate unless an author specifically requests otherwise. Rejection by one section editor is considered rejection by all, therefore a manuscript rejected by one section editor should not be submitted to another. 